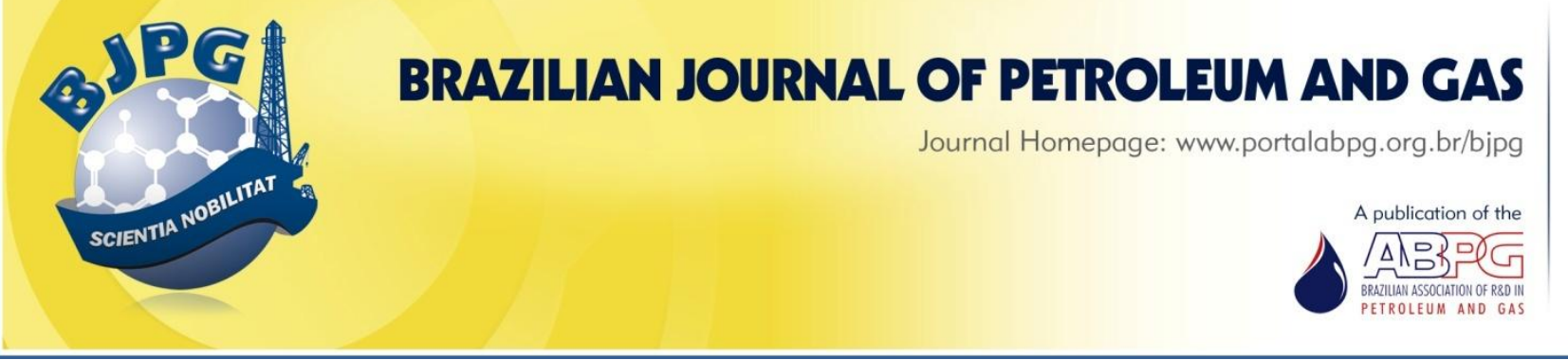

\title{
CATALYTIC REMOVAL OF SULFUR COMPOUNDS FROM PETROLEUM STREAMS
}

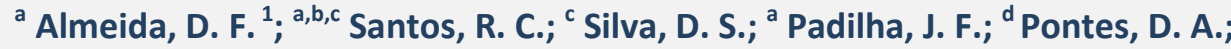 \\ a,b Pontes, L. A. M.
}

${ }^{a}$ Federal University of Bahia - UFBA, Graduate Program of Chemical Engineering, Salvador - BA - Brazil

${ }^{b}$ Brazilian Institute of Technology and Regulation - IBTR, Salvador - BA - Brazil

${ }^{C}$ Salvador University - UNIFACS - Department of Chemical Engineering, Salvador - BA - Brazil

${ }^{d}$ Federal University of São Carlos - UFSCAR, Department of Chemical Engineering, São Carlos - SP - Brazil

Received: 10.08.2018 / Revised: 27.08.2018 / Accepted: 28.08.2018 / Published on line: 17.10.2018

\begin{abstract}
Sulfur removal aiming at attending environmental legislation standards has been the focus of many studies. The use of Fluid Catalytic Cracking, FCC, in the removal of gasoline-fraction sulfur contaminants is regarded as advantageous when compared to desulfurization processes downstream of the FCC process. This paper evaluates the effect of $\mathrm{Mg}$ addition to the Beta zeolite over $\mathrm{n}$-hexane and thiophene cracking. The catalysts were characterized by X-ray diffraction (XRD), X-ray with dispersive energy fluorescence analysis (EDXRF), Fourier transform infrared spectroscopy (FTIR), ammonia temperature programmed desorption ( $\mathrm{NH}_{3}-\mathrm{TPD}$ ), and Brunauer-Emmett-Teller method (BET). The magnesium incorporation into the zeolite increased the number of Brønsted active sites and total acidity in the catalyst, favoring an increase in selectivity for catalytic cracking reactions and a decrease of isomerization reactions in the $n$-hexane conversion step. In thiophene conversion, the greater selectivity for hydrogen transfer promoted the formation of $\mathrm{H}_{2} \mathrm{~S}$, and adsorptive capacity is a key factor in alkylated product formation due to the presence of Lewis active sites, which are more predominant in magnesium incorporated catalysts.
\end{abstract}

\section{KEYWORDS}

beta zeolite; magnesium; thiophene; catalytic cracking; hydrogen transfer

\footnotetext{
${ }^{1}$ To whom all correspondence should be addressed.

Address: Universidade Federal da Bahia, PPEQ - Programa de Pós-graduação em Engenharia Química, Escola Politécnica, R. Prof. Aristídes Novis, 2, Federação, Bahia, Brasil.

ZIP Code: 40210-630 | Telephone: + 5571 99977-6931 | e-mail: danielfreire88@hotmail.com doi:10.5419/bjpg2018-0017
} 


\section{INTRODUCTION}

Fluid catalytic cracking - FCC is one of the main fuel production processes in a refinery. In this process, heavy petroleum compounds are cracked into lighter compounds and added to the pool of gasoline, diesel, aviation kerosene, or liquefied petroleum gas - LPG (Clough et al., 2017).

The sulfur contained in petroleum is related to the amount of heavy aromatic compounds of high boiling point, which compose the distillation residue. In petroleum-derived fuels, the presence of sulfurized compounds implies higher emissions of primary pollutants, $\mathrm{SO}_{\mathrm{x}}$, which cause disturbances to human health and the environment (Castro Dantas et al., 2014; Morais et al., 2010).

Several countries have set sulfur content limits in fuel reduction strategies with more rigorous environmental regulation (Iruretagoyena \& Montesano, 2018). This trend will continue in the next few years. As a consequence, in order to achieve such higher demands for oil derivatives, sulfurized compounds treatment technologies are essential for the entire oil industry (Bajia et al., 2017).

The resulting stream of the FCC process represents 30 to 35 vol\% of the total gasoline amount produced in a refinery. In this stream, an average $90 \%$ of sulfurized compounds are concentrated in the gasoline pool (Karthikeyani et al., 2017; Vargas-Tah et al., 2005).

Separation and conversion processes downstream of FCC aim at improving product quality while suppressing contaminants. The most notable separation and conversion process is Hydrodesulfurization - HDS (Brunet et al., 2005). However, other processes, either isolated or combined, can be used for sulfur reduction in liquid fuels and refinery streams, such as Adsorption Desulfurization - ADS (Dehghan \& Anbia, 2017), Extractive Desulfurization - EDS (Abro et al., 2014), Bio-desulfurization - BDS (Nuhu, 2013), Oxidative Desulfurization - ODS (Bhutto et al., 2016), Desulfurization by Precipitation, and Desulfurization using lonic Liquids (Ibrahim et al., 2017). Hydrodesulfurization is the most common and effective process used to meet sulfur reduction specifications and olefins in gasoline. Nevertheless, besides raising fuel-processing costs, it reduces octane rating (Ahmad, 2016; Castro Dantas et al., 2014; Santos et al., 2013).
On the other hand, new additives have been applied directly to the FCC catalyst core for gasoline sulfur reduction - GSR (Bryden et al., 2015; Clough et al., 2017; Karthikeyani et al., 2017). Several metals, such as $\mathrm{Mg}, \mathrm{Al}, \mathrm{Zn}, \mathrm{Ni}, \mathrm{Cu}$, and $\mathrm{Ag}$, in the form of their pure oxides, mixed oxides, spinel structures, and modified zeolites have been tested. Additives to FCC catalysts bring some advantages, such as octane number preservation; ease of operation; petroleum selection flexibility; hydrogen consumption reduction; and longer lifespan for post FCC desulfurization catalysts. Besides, its use can be advantageous for refineries, because it minimizes the need for additional costly structures, such as HDS (Potapenko et al., 2012; Siddiqui et al., 2006). A potential additive for gasoline sulfur removal is the Beta zeolite modified with metals, which allows greater adsorption of sulfurized compounds (Gong et al., 2009; Tian et al., 2012). According to Corma et al. (1995), the beta zeolite has high selectivity due to the relative ease of reactant diffusion in its pores, which reinforces the assumption that it can be used in the FCC process.

In the FCC process, besides cracking reactions, several parallel and sequential reactions occur among the primary cracking products. An important secondary reaction is hydrogen transfer $(\mathrm{HT})$, which promotes hydrogen exchange among hydrocarbons, with an increase in saturation of some of them, and, consequentially, the formation of olefins, aromatics, and coke precursors. HT has positive effects on the gasoline fraction of FCC, and negative effects on fractions destined to the diesel pool and light olefins destined to the petrochemical plant.

The hydrogen transfer capacity (HT) to the Beta zeolite is inferior to that of the $Y$ zeolite, although still relatively high when compared to ZSM-5. One of the Beta zeolites' HT reaction selectivity adjustment alternatives would be modification with alkaline-earth cations.

In this context, this paper aims at evaluating the effect of magnesium incorporation into Beta zeolites in thiophene cracking in an $n$-hexane stream. 


\section{MATERIALS AND METHODS}

The experiments used a commercial ammonium Beta zeolite (BEA - CP814N) from Zeolyst International with SAR 18 and $\mathrm{Na}_{2} \mathrm{O} / \mathrm{Al}_{2} \mathrm{O}_{3}=0.01$ $\mathrm{mol} / \mathrm{mol}$ ratio. The zeolite in its protic form was obtained after drying at $130{ }^{\circ} \mathrm{C}$ followed by calcination for 4 hours in a muffle furnace with air flow, at $500{ }^{\circ} \mathrm{C}$. The resulting $\mathrm{H}$-Beta was then modified by magnesium incorporation through diffusional impregnation and cationic exchange.

Magnesium nitrate hexahydrate $\left(\mathrm{Mg}\left(\mathrm{NO}_{3}\right)_{2} \cdot 6 \mathrm{H}_{2} \mathrm{O}\right)$, Sigma-Aldrich/Vetec (P.A., 99\%) was used as an alkaline-earth metal source.

The magnesium impregnation process was performed to achieve a metal/aluminum molar relation of 0.2 in the zeolite. The contact time between the precursor solution and the solid was 24 hours, at room temperature. Henceforth, the system was submitted to a vacuum at $70^{\circ} \mathrm{C}$ until total evaporation of the aqueous phase. The material was then dried in the oven at $100{ }^{\circ} \mathrm{C}$, for 24 hours, and calcinated for 4 hours in a muffle furnace with air flow, at $500{ }^{\circ} \mathrm{C}$.

For the cationic exchange process, $\mathrm{H}$-Beta was added to a magnesium solution $0.1 \mathrm{M}$ and kept under constant stirring at room temperature, for 48 hours. After filtration, the solid was washed with deionized water, dried, and calcinated.

The Beta zeolite in its protonic form was named $H \beta$. The catalysts prepared by impregnation and ionic exchange were named $\mathrm{Mg} \beta \mathrm{I}$ and $\mathrm{Mg} \beta \mathrm{E}$, respectively.

The aluminum contents were determined by sample opening with $\mathrm{HF}$, and complexometric titration with EDTA by zinc sulfate return using Eriochrome black $\mathrm{T}$ as indicator. The silicon content estimates in the zeolites were obtained by difference in the formula in zeolite starter oxides, considering:

$\mathrm{xNa}_{2} \mathrm{O} \cdot(1-\mathrm{x}) \mathrm{H}_{2} \mathrm{O} \cdot \mathrm{Al}_{2} \mathrm{O}_{3} \cdot \mathrm{zSiO}_{2}$

Where: $\mathrm{z}=\mathrm{SAR}=\mathrm{Al}_{2} \mathrm{O}_{3} / \mathrm{SiO}_{2}$

Sodium and magnesium contents were determined by X-ray with dispersive energy fluorescence analysis (EDFRX) in a Bruker model S2 Ranger equipment with helium flow. The contents were exposed for 200 seconds and radiation source operating conditions were specified for each indicated chemical element ( $\mathrm{Si}, \mathrm{Al}$, and $\mathrm{Mg}$ ).

The surface area and pore size distribution were measured through a Quantachrome model Nova2000 equipment, through $\mathrm{N}_{2}$ adsorption at $96{ }^{\circ} \mathrm{C}$. Surface area was determined using the BET method (Brunauer-Emmett-Teller). Pore size was measured using the BJH methodology (BarrettJoyner- Halenda) for adsorption isotherms. In the analysis, $0.1 \mathrm{~g}$ of sample was pretreated at $300{ }^{\circ} \mathrm{C}$ under vacuum for 1 hour in each.

The characterization of samples by X-ray diffraction (XRD) was performed to identify the relative crystallinity. The determination of crystallographic standards present in the catalysts was performed in a Shimadzu model XRD 6100 diffractometer with a $\mathrm{Cu}-\mathrm{K} \alpha$ tube at $40 \mathrm{kV}$ and 30 $m A$, with a sample drawer specific for powder like material. The diffractograms were obtained in the $2 \theta$ range between 5 and $80^{\circ}$, with a scanning speed of $2^{\circ} \mathrm{min}^{-1}$ and $0.02^{\circ}$ step at every $0.6 \mathrm{~s}$.

The characterization by Fourier transform infrared spectroscopy (FTIR) was performed in a Perkin Elmer spectrophotometer model Spectrum One, with a wave number reading between 4000 and $400 \mathrm{~cm}^{-1}$, with 32 scans per sample.

The characterization by ammonia temperature programmed desorption ( $\mathrm{NH}_{3}$-TPD) for acidic site strength distribution analysis was performed in a multipurpose analytic system (SAMP). The samples (100mg) were pretreated at $400{ }^{\circ} \mathrm{C}$ in a He atmosphere for $40 \mathrm{~min}$ and then exposed to a flux of $30 \mathrm{~mL} / \mathrm{min}$ of a gaseous mixture of $2 \% \mathrm{NH}_{3}$ and $98 \% \mathrm{He} \mathrm{mol} / \mathrm{mol}$ at $100{ }^{\circ} \mathrm{C}$ for $45 \mathrm{~min}$. For desorption of physisorbed compounds, the sample was kept at $100{ }^{\circ} \mathrm{C}$ for 60 minutes under He flow. A heating ramp of $10^{\circ} \mathrm{C} / \mathrm{min}$ up to $800^{\circ} \mathrm{C}$ was applied for the desorbed ammonia measurement in $\mu$ mols of $\mathrm{NH}_{3} / \mathrm{g}_{\text {cat }}$.

The catalytic behavior was evaluated, in gaseous phase, in a system containing a glass tubular reactor of $10 \mathrm{~mm}$ diameter at a temperature of $500{ }^{\circ} \mathrm{C} .5 \mathrm{mg}$ of catalysts were pretreated in a nitrogen atmosphere at $500{ }^{\circ} \mathrm{C}$ for 2 hours before each test. The reactants were fed via a high performance infinite isocratic dosing pump model 1260 Infinity Series, Agilent Technologies. The reaction mixture flow rates of each experiment 
were adjusted to obtain a space velocity (WHSV) of $0.83 \mathrm{~s}^{-1}$.

The reactional mixture was attested to be composed of $100 \mathrm{ppm}$ thiophene (99\% reactant A.C.S., Sigma-Aldrich) in $n$-hexane ( $\geq 99 \%$ reactant A.C.S., Sigma-Aldrich). Thiophene was used as a model molecule representing organosulfur compounds and $\mathrm{n}$ - hexane as a gasoline-fraction paraffinic compound.

The effluent was analyzed through a gas chromatographer model 7890B, Agilent Technologies, with automatic sampling, flame ionization detector (FID) for determining hydrocarbons and sulfur by chemiluminescence with a double plasma burner (SCD-DP). For hydrocarbon separation, a capillary column Alumina Chloride Plot, $50 \mathrm{~m} \times 0.32 \mathrm{~mm} \times 5 \mu \mathrm{m}$, Supelco, was used with a split ratio of 400:1. For sulfur compounds separation, a capillary column DB-Sulfur SCD, $40 \mathrm{~m} \times 0.32 \mathrm{~mm} \times 0.75 \mu \mathrm{m}$, Agilent Technologies, with a split ratio of 100:1 was used.

Catalyst Brønsted acidity analysis was determined by an $\alpha$ test, with pure $n$ - hexane, measuring protolithic hydrocarbon cracking, and indirectly determining the catalytic activity and acidic Brønsted site strength (Farneth \& Gorte, 1995; Hopkins et al., 1988; Knott et al., 2018; Olson, 1980).

In the $\alpha$ test, operating conditions were: space velocity of $0.83 \mathrm{~s}^{-1}$, at a temperature of $500{ }^{\circ} \mathrm{C}$ and atmospheric pressure. The result was calculated according to the equation below:

$-\mathrm{r}_{\mathrm{nC} 6}=\frac{\mathrm{F}_{\mathrm{nC} 6}^{0} \cdot \mathrm{X}_{\mathrm{nC} 6}}{\mathrm{~W}}$

Where:

$-r_{\mathrm{nc}}=\mathrm{n}$-hexane conversion index $\left(\mathrm{mol} . \mathrm{g}^{-1} \cdot \mathrm{h}^{-1}\right)$;

$\mathrm{F}_{\mathrm{nC6}}^{0}=$ molar feed flow rate of $\mathrm{n}$-hexane $\left(\mathrm{mol} . \mathrm{h}^{-1}\right)$;

$\mathrm{X}_{\mathrm{nc6}}=$ conversion of $\mathrm{n}$-hexane;

$\mathrm{W}=$ catalyst mass $(\mathrm{g})$.

The catalyst relative activity index was normalized from the catalyst conversion rate divided by the $H \beta$ catalyst rate:
$-\mathrm{rnC6}^{*}=\frac{\left(-\mathrm{r}_{\mathrm{nC} 6}\right)_{\mathrm{cat}}}{\left(-\mathrm{r}_{\mathrm{nC} 6}\right)_{\mathrm{H} \beta}}$

Where:

$-r_{\text {nc6 }}{ }^{*}=$ relative activity index;

$\left(-r_{n c 6}\right)_{c a t}=n$-hexane conversion index for each magnesium catalyst;

$\left(-r_{n C 6}\right)_{H \beta}=n$-hexane conversion index for Beta zeolite in protonic form.

The determination of $\mathrm{n}$-hexane and thiophene conversions were made using the equations below:

$\mathrm{X}_{\mathrm{nC} 6}=\frac{\mathrm{n}_{\mathrm{nC} 6}^{\mathrm{o}}-\mathrm{n}_{\mathrm{nC} 6}}{\mathrm{n}_{\mathrm{nC} 6}^{\mathrm{o}}} \cdot 100$

Where:

$\mathrm{X}_{\mathrm{nC6}}=$ conversion of $\mathrm{n}$-hexane (\%);

$\mathrm{n}^{\mathrm{o}}{ }_{\mathrm{nC6}}=$ inlet $\mathrm{n}$-hexane molar flow rate;

$\mathrm{n}_{\mathrm{nc6}}=$ outlet $\mathrm{n}$-hexane molar flow rate.

$\mathrm{X}_{\mathrm{C} 4 \mathrm{H} 4 \mathrm{~S}}=\frac{\mathrm{n}_{\mathrm{C} 4 \mathrm{H} 4 \mathrm{~S}}^{\mathrm{o}}-\mathrm{n}_{\mathrm{C} 4 \mathrm{H} 4 \mathrm{~S}}}{\mathrm{n}_{\mathrm{C} 4 \mathrm{H} 4 \mathrm{~S}}^{\mathrm{d}}} .100$

Where:

$\mathrm{X}_{\mathrm{C} 4 \mathrm{H} 4 \mathrm{~S}}=$ conversion of thiophene (\%);

$\mathrm{n}^{\circ}{ }_{\text {C4H4S }}=$ inlet thiophene molar flow rate;

$\mathrm{n}_{\mathrm{C} 4 \mathrm{H} 4 \mathrm{~S}}=$ outlet thiophene molar flow rate.

The determination of hydrocarbons and sulfur compounds selectivity were made using the equations below:

Sel $_{. i(H C)}=\frac{n_{i(H C)}}{n_{n C 6}^{o}-n_{n C 6}} \cdot 100$

Where:

Sel $_{. i(\mathrm{HC})}=$ selectivity for each hydrocarbon (\%);

$n_{i}(\mathrm{HC})=$ outlet molar flow rate for each hydrocarbon.

Sel.i $_{\cdot(S)}=\frac{n_{i(S)}}{n_{C 4 H 4 S}^{0}-n_{C 4 H 4 S}} \cdot 100$

Where:

Sel. ${ }_{i(s)}=$ selectivity for each sulfur compound (\%); 
$n_{i(s)}=$ outlet molar flow rate for each sulfur compound.

The hydrogen transfer index was measured through $\mathrm{n}$-hexane cracking, under low conversion circumstances, from the isobutane and isobutene formation rates. In this paper, this parameter was measured according the equation proposed by Lukyanov (1994):

$\mathrm{I}_{\mathrm{HT}}=\mathrm{k}_{\mathrm{HT}}^{*}=\mathrm{k}_{\mathrm{HT}} \mathrm{k}_{\mathrm{a}}=\frac{\mathrm{r}_{\mathrm{iC} 4}}{\left[\mathrm{nC}_{6}\right] \cdot\left[\mathrm{iC}_{4}^{=}\right]}$

Where:

$\mathrm{I}_{\mathrm{HT}}=\mathrm{k}_{\mathrm{HT}}^{*}=$ hydrogen transfer index

$r_{i c 4}=$ rate of isobutane formation $\left(\mathrm{mol} \cdot \mathrm{g}^{-1} \cdot \mathrm{h}^{-1}\right)$

$\mathrm{k}_{\mathrm{HT}}=$ rate constant of the hydride transfer step

$\mathrm{k}_{\mathrm{a}}=$ adsorption constant for isobutene

$\left[\mathrm{nC}_{6}\right]=\mathrm{n}$-hexane concentration in the reaction mixture

$\left[\mathrm{iC}_{4}{ }^{\overline{ }}\right]=$ isobutene concentration in the reaction mixture

Those measurable variables were calculated from concentration measurements in the reactor inlet and outlet, operating in the differential regime. The rate of isobutane formation was calculated using the equation below:

$\mathrm{r}_{\mathrm{iC} 4}=\frac{\mathrm{F}_{\mathrm{iC} 4}}{\mathrm{~W}}$

Where:

$\mathrm{F}_{\text {ic4 }}=$ molar flow rate of isobutane in the outlet $\left(\mathrm{mol} . \mathrm{h}^{-1}\right)$.

The molar flow rate of isobutane in the outlet was calculated from the total mass flow rate, the isobutane mass concentration, and isobutane molecular weight. The HT indexes were relatively compared, and normalized by the $\mathrm{H} \beta$ sample index, as follows:

$\mathrm{I}_{\mathrm{HT}}{ }^{*}=\frac{\left(\mathrm{I}_{\mathrm{HT}}\right)_{\mathrm{cat}}}{\left(\mathrm{I}_{\mathrm{HT}}\right)_{\mathrm{H} \beta}}$

Where:

$\mathrm{I}_{\mathrm{HT}}{ }^{*}=$ relative hydrogen transfer index;

$\left(I_{H T}\right)_{c a t}=$ hydrogen transfer index for each magnesium catalyst;

$\left(I_{H T}\right)_{H \beta}=$ hydrogen transfer index for Beta zeolite in protonic form.

\section{RESULTS AND DISCUSSION}

\subsection{Catalyst characterization}

Texture analysis and chemical composition of catalysts are shown in Table 1 . The molar ratios $\mathrm{SiO}_{2} / \mathrm{Al}_{2} \mathrm{O}_{3}$ and $\mathrm{MgO} / \mathrm{Al}_{2} \mathrm{O}_{3}$ obtained by impregnation or cationic exchange were similar. This indicates that, in the ionic exchange and impregnation conditions used, equilibrium concentrations in the phases were very favorable to the transfer of almost all cations in solution to the zeolite. This was also true for aluminum charge compensation, considering that, in ionic exchange, the cation is incorporated only in aluminum charge compensation positions. Nevertheless, in impregnation it also deposits on the surface as nitrate and, then, it is converted into oxide during calcination.

The adsorption-desorption nitrogen isotherms of catalysts $\mathrm{H} \beta, \mathrm{Mg} \beta \mathrm{I}$, and $\mathrm{Mg} \beta \mathrm{E}$, shown in Figure 1 are typical Type IV isotherms, with Type H4 hysteresis. At high relative pressure (between 0.8 and 1.0 $\left.\mathrm{P} / \mathrm{P}_{0}\right)$, an increase in adsorbed nitrogen was observed, suggesting a contribution of the external surface area. The results were similar in all three

Table 1. Catalyst properties.

\begin{tabular}{cccc}
\hline Property & $\mathbf{H} \boldsymbol{\beta}$ & $\mathbf{M g} \boldsymbol{\beta} \mathbf{~}$ & $\mathbf{M g} \boldsymbol{\beta E}$ \\
\hline $\mathrm{SiO}_{2} / \mathrm{Al}_{2} \mathrm{O}_{3}$ & 18 & 19.0 & 17.6 \\
$\mathrm{MgO}_{\mathrm{Al}} \mathrm{O}_{3}$ & 0.00 & 0.21 & 0.16 \\
Surface area $-\mathrm{BET}\left(\mathrm{m}^{2} / \mathrm{g}\right)$ & 560 & 505 & 525 \\
Pore Size $-\mathrm{BJH}\left(\mathrm{cm}^{3} / \mathrm{g}\right)$ & 0.42 & 0.49 & 0.49 \\
\hline
\end{tabular}




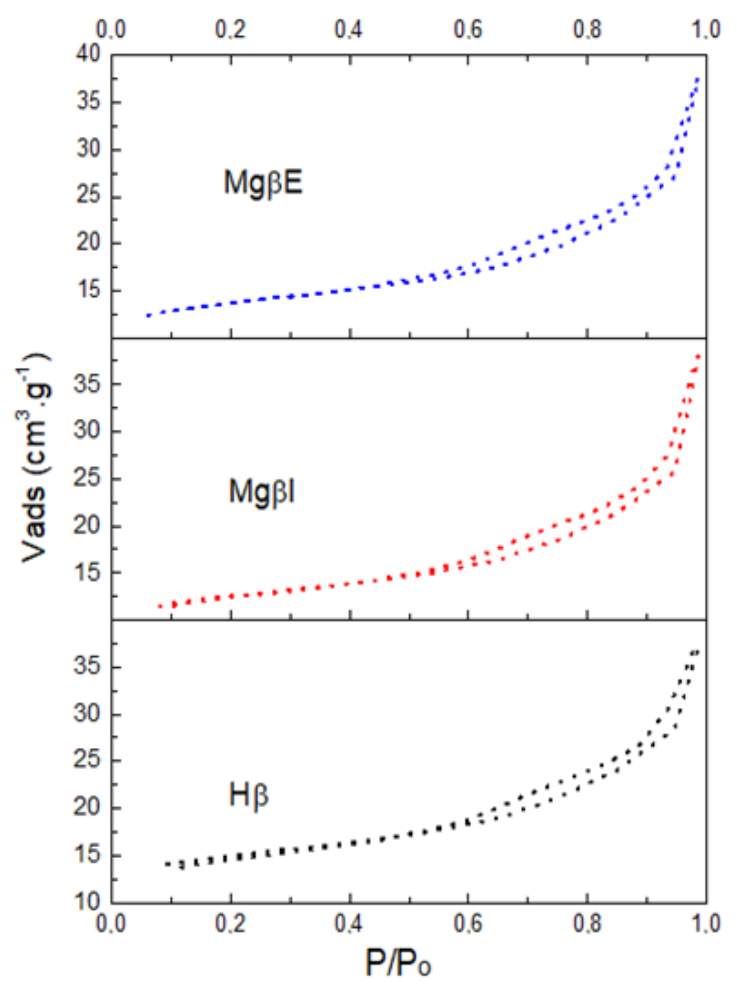

Figure 1. $\mathrm{N}_{2}$ adsorption-desorption isotherms in the modified Beta zeolites.

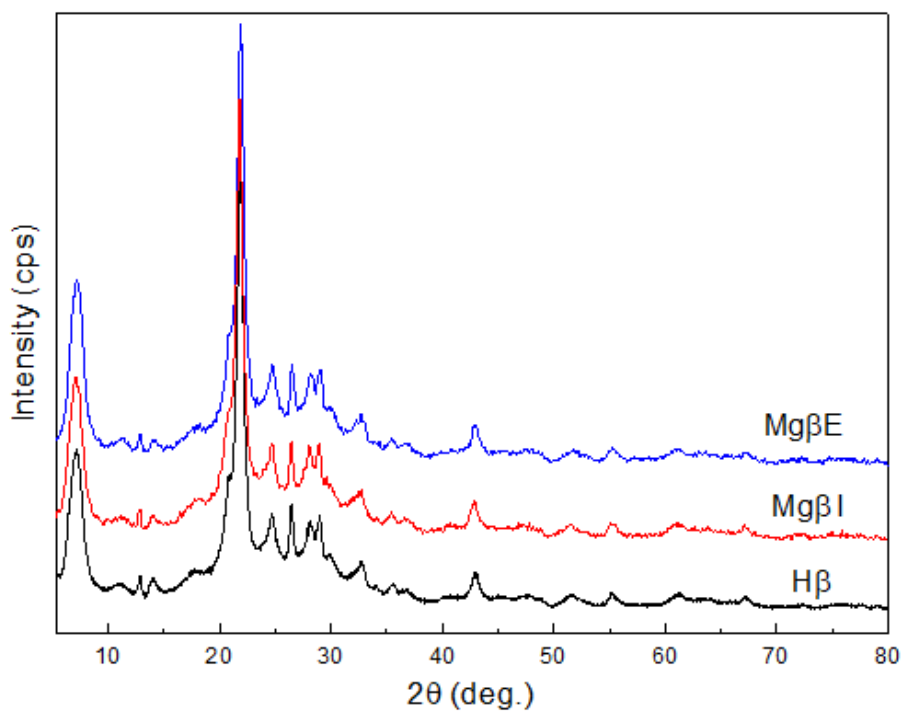

Figure 2. XRD powder diffractograms obtained for the catalysts.

samples, i.e. the introduction of magnesium, whether by ionic exchange or by impregnation, did not change microporosity.

Comparing sample surface areas, slight changes after magnesium incorporation into the Beta zeolite are observed, but are unrepresentative, because they are due, in part, to the increase in mass of the resulting crystals of proton replacement by magnesium in the unit cell. Based on the observation, one can conclude that the magnesium addition did not promote texture modifications in the BEA zeolite.

The catalysts' X-ray diffractograms (Figure 2), presented peaks at $2 \theta=7.5^{\circ}, 16.2^{\circ}, 21.2^{\circ}, 22.1^{\circ}$, $26.8^{\circ}, 29.4^{\circ}$, and $43.1^{\circ}$. According to the International Center for Diffraction Data (ICDD) 


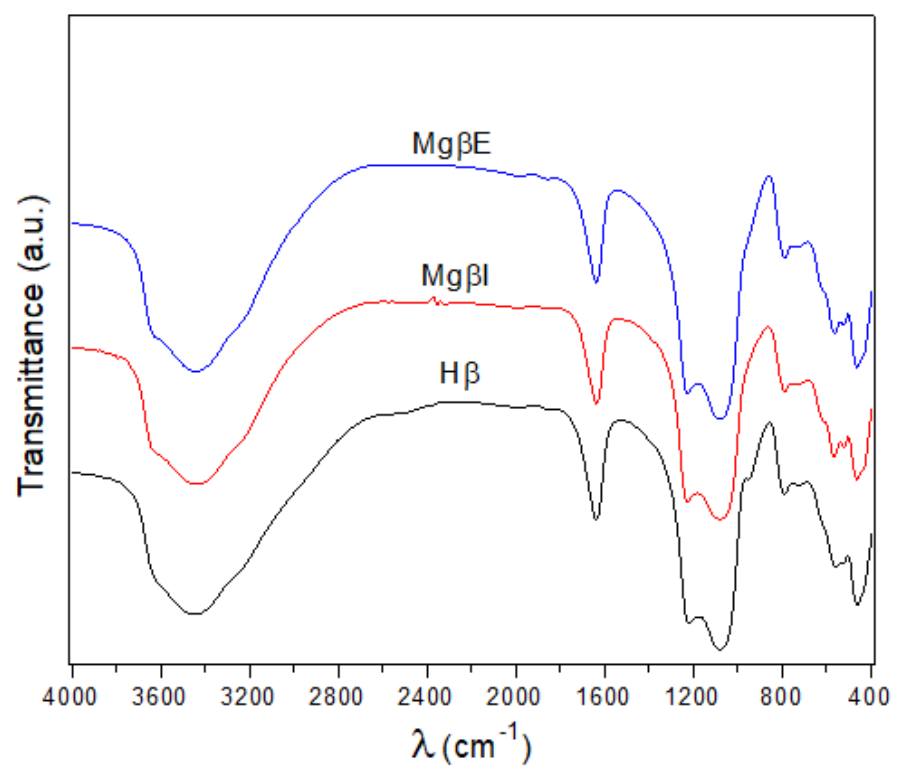

Figure 3. Infrared spectrogram of the proposed catalysts.

database standards, these are relative to Beta zeolite phases. No difference was observed on $H \beta$, $\mathrm{Mg} \beta \mathrm{I}$, and $\mathrm{Mg} \beta \mathrm{E}$ catalyst diffractograms. In light of these results, one can infer that magnesium incorporation by both routes does not alter structure or material's degree crystallinity.

The spectra in the catalysts' infrared region (Figure 3) were similar and presented peaks characteristic of the Beta zeolite $\left(520\right.$ and $\left.560 \mathrm{~cm}^{-1}\right)$, referent to 5- and 6-member rings T-O-T ( $\mathrm{T}=\mathrm{Si}$ or Al), with approximately the same intensities for all samples. The bands attributed to the vibrational modes of the bond bending $\mathrm{T}-\mathrm{O}$, of the external symmetric stretching of O-T-O and of external and internal asymmetric stretching of O-T-O, (respectively, 460, 785, 1070, and $1220 \mathrm{~cm}^{-1}$ ) are typical of the zeolite crystalline structure, formed by $\mathrm{TO}_{4}$ tetrahedral $(\mathrm{T}=\mathrm{Si}, \mathrm{Al})$. The bands at 3445 $\mathrm{cm}^{-1}$ and peak at $1635 \mathrm{~cm}^{-1}$ are attributed to bending vibration of adsorbed water on the surface (Peng et al., 2017; Thankur et al., 2016; Zhang et al., 2014).

Figure 4 shows $\mathrm{NH}_{3}$-TPD curves indicating ammonia desorption in two temperature zones. The first one from 300 to $600 \mathrm{~K}$ related to weak active sites, and the second from 600 to $950 \mathrm{~K}$ related to moderate-strong active sites.

The TPD curve profile for $H \beta$, shown in Figure 4, presents peaks associated with weak and medium acidity. Similar results were observed by Lónyi and Valyon (2001) and Hernando et al. (2017).

Deconvolution quantitative peak analyses are presented in Table 2.

Table 2. Summary of the catalysts' acidity.

\begin{tabular}{cccc}
\hline Acid sites & $\mathbf{H} \boldsymbol{\beta}$ & $\mathbf{M g} \boldsymbol{\beta} \mathbf{~}$ & $\mathbf{M g} \boldsymbol{\beta E}$ \\
\hline Weak (\%) & 52.0 & 48.9 & 44.9 \\
Medium(\%) & 43.7 & 33.3 & 40.1 \\
Strong (\%) & 4.3 & 17.8 & 15.0 \\
Medium + strong (\%) & 48.0 & 51.1 & 55.1 \\
Total acid sites ( $\mu$ mols de NH${ }_{3} / \mathrm{g}_{\text {cat }}$ ) & 1419 & 1582 & 1607 \\
\hline Relative medium + strong sites & 1.00 & 1.06 & 1.15 \\
Relative total acid sites amount & 1.00 & 1.11 & 1.13 \\
\hline
\end{tabular}




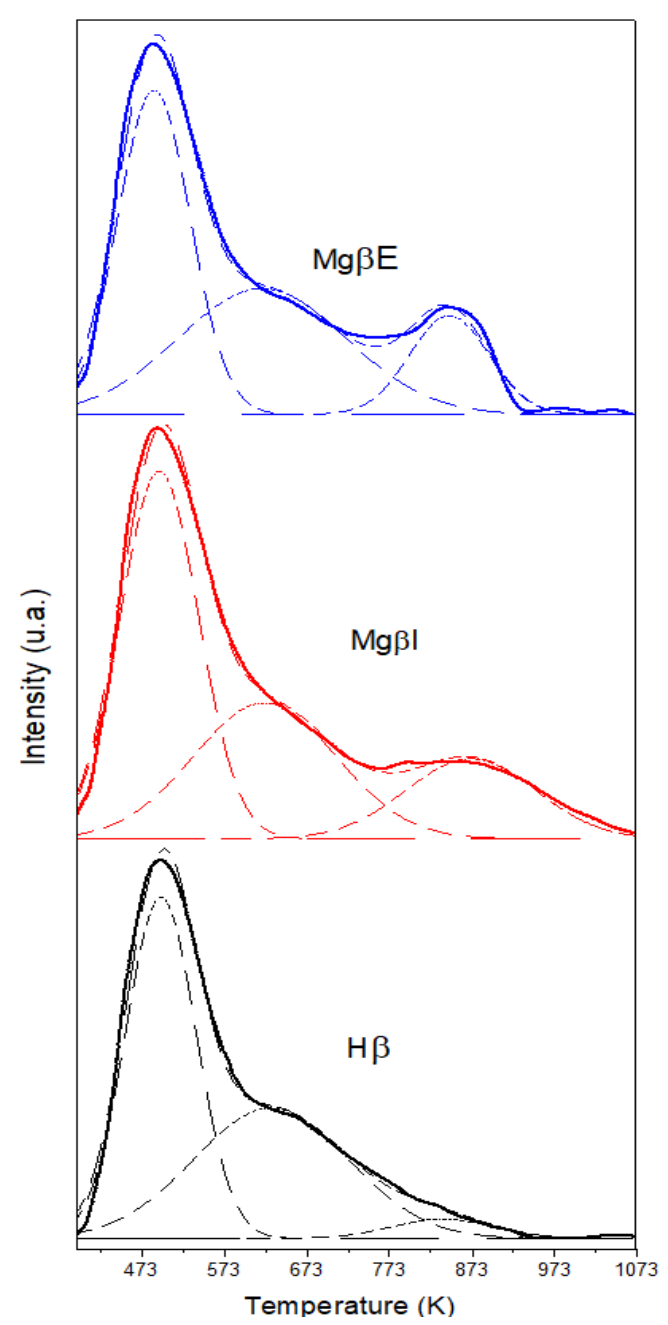

Figure 4. $\mathrm{NH}_{3}$-TPD catalysts curves.

After magnesium incorporation, an increase in the third peak at high temperatures and the decrease of medium and weak acidity peaks are observed (Table 2). Such behavior suggests the substitution of weak and medium sites in $\mathrm{H} \beta$ by the species formed by magnesium addition. The incorporation of magnesium, whether through ionic exchange or impregnation, resulted in an average increase of $12 \%$ in the total number of acidic sites when compared to $\mathrm{H} \beta$.

In $\mathrm{Mg} \beta \mathrm{E}$ and $\mathrm{Mg} \beta \mathrm{I}$ catalysts, a change in active site strength distribution was observed, in which there was a significant increase in the number of strong active sites over moderate and weak ones.

According to Mirodatos et al. (1976) and Ward (1968), magnesium addition to $\mathrm{NaH}-\mathrm{Y}$ zeolites increased Brønsted and Lewis catalyst acidity. This fact may be attributed to the formation of $\mathrm{H}^{+}$and $\mathrm{Mg}(\mathrm{OH})^{+}$species resulting from cation hydrolysis followed by water molecules dissociation at high temperatures.

$\mathrm{Mg}^{2+}+\mathrm{H}_{2} \mathrm{O} \leftrightharpoons \mathrm{Mg}\left(\mathrm{OH}_{2}\right)^{2+} \leftrightharpoons \mathrm{MgOH}^{+}+\mathrm{H}^{+}$

\section{2 n-Hexane cracking}

Relative activity index results by the $\alpha$ test (Equation 3) are presented in Table 3.

Results from the $\alpha$ test were coherent with total acidity replacement measured by ammonia TPD. $\mathrm{Mg}$ incorporation into the zeolite promoted an increase in catalytic activity of n-hexane cracking. The measured relative activity increased in the following order: $\mathrm{H} \beta<\mathrm{Mg} \beta \mathrm{I}<\mathrm{Mg} \beta \mathrm{E}$. Strong + medium sites concentration, particularly, also obeyed this order.

Relative selectivity for HT reactions was also verified, shown as $I_{T H}{ }^{*}$ (Equation 10), to have decreased magnesium addition in catalysts. Magnesium is unfavorable to parallel and sequential hydrogen transfer reactions, despite favoring activity. This suggests that the corresponding species to acidic sites formed by magnesium addition are not as effective for HT reactions as protic peaks from the $H \beta$ zeolite. One can infer that magnesium addition to the zeolite resulted in an increase in Brønsted acidic sites in catalysts, since the $\alpha$ test is a measurement of these sites' activity (Knott et al., 2018; Zhang \& Maesen, 2018).

Table 3. $\alpha$ test results, and $\mathrm{Mg}$ incorporation effect.

\begin{tabular}{cccc}
\hline Parameter & $\mathbf{H} \boldsymbol{\beta}$ & $\mathbf{M g} \boldsymbol{\beta} \mathbf{~}$ & $\mathbf{M g} \boldsymbol{\beta E}$ \\
\hline $\mathrm{MgO} / \mathrm{Al}_{2} \mathrm{O}_{3}$ & 0.00 & 0.21 & 0.16 \\
Relative total acid sites & 1.00 & 1.11 & 1.13 \\
Relative medium + strong acid sites & 1.00 & 1.06 & 1.15 \\
$-{ }^{*}{ }_{n C 6}$ & 1.00 & 1.11 & 1.21 \\
$I_{H T}{ }^{*}$ & 1.00 & 0.91 & 0.92 \\
\hline
\end{tabular}


Table 4. Results of catalytic tests for $n$-hexane.

\begin{tabular}{|c|c|c|c|}
\hline Parameter & $H \beta$ & $\mathrm{Mg} \beta \mathbf{I}$ & $M g \beta E$ \\
\hline $\mathrm{MgO} / \mathrm{Al}_{2} \mathrm{O}_{3}$ & 0.00 & 0.21 & 0.16 \\
\hline \multirow[t]{2}{*}{$I_{T H}{ }^{*}$} & 1.0 & 0.91 & 0.92 \\
\hline & \multicolumn{2}{|c|}{ Selectivity (\%mol) } & \\
\hline Cracking & 76.7 & 78.1 & 89.7 \\
\hline Isomerization & 20.2 & 18.3 & 8.1 \\
\hline Dehydrogenation & 0.7 & 0.4 & 0.4 \\
\hline Cyclization & 1.4 & 1.9 & 1.6 \\
\hline Oligomerization & 1.0 & 1.3 & 0.2 \\
\hline
\end{tabular}

Table 5. Selectivity of catalytic tests to sulfur compounds.

\begin{tabular}{cccc}
\hline Parameter & $\mathbf{H} \boldsymbol{\beta}$ & $\mathbf{M g} \boldsymbol{\beta} \mathbf{~}$ & $\mathbf{M g} \boldsymbol{\beta E}$ \\
\hline $\mathrm{MgO} / \mathrm{Al}_{2} \mathrm{O}_{3}$ & 0.00 & 0.21 & 0.16 \\
$\mathrm{I}_{\mathrm{TH}}{ }^{*}$ & 1.00 & 0.91 & 0.92 \\
& & Selectivity (\%mol) & \\
$\mathrm{H}_{2} \mathrm{~S}$ & 85.6 & 76.8 & 67.1 \\
Mercaptans & 6.5 & 4.5 & 4.5 \\
Alkylation products & 7.5 & 18.2 & 23.4 \\
Condensation products & 0.3 & 0.1 & 4.8 \\
Tetrahydrothiophene & 0.0 & 0.4 & 0.2 \\
\hline
\end{tabular}

\subsection{Test reaction with thiophene and hexane}

In Tables 4 and 5 , the selectivity for catalytic tests with $\mathrm{n}$-hexane charge in a mixture with 100 ppm thiophene results is presented at $500{ }^{\circ} \mathrm{C}$, atmospheric pressure, and low conversion conditions $(<10 \%)$.

Table 4 shows the selectivity for cracking products $\left(\begin{array}{lll}\mathrm{C}_{1} & \mathrm{a} & \mathrm{C}_{5}\end{array}\right)$, isomerization $\left(\mathrm{iC}_{6}\right)$, dehydrogenation (mono and diolefins), cyclizing (naphthenics), the formation of heavies (oligomers), and relative HT index $\left(I_{T H}{ }^{*}\right)$.

In hexane conversion, cracking selectivity obeys the same active site strength sequence shown by ammonia TPD: $\mathrm{H} \beta<\mathrm{Mg} \beta \mid<M g \beta E$. The selectivity for isomerization follows the inverse selectivity order for cracking.

Hydrocarbon cracking occurs in Brønsted acidic sites, and there is a direct relationship between catalytic activity and acidic site strength (Corma \& Sauvanaud, 2013; Potapenko et al., 2016). Selectivity for cracking products and/or isomerization is sensitive to zeolite structure, Brønsted acidic sites' nature and strength, and reaction conditions. Lersch and Banderman (1991), while studying alkaline-earth cations incorporation effects by impregnation or ionic exchange in ZSM5 , concluded that alkaline-earth metal addition increases the number of strong acidic sites in catalysts.

Pusparatu et al. (2012) while studying n-hexane isomerization and cracking reactions on several zeolites, observed that the Beta zeolite presented a higher activity and selectivity for hexane isomerization when compared to $\mathrm{MWW}, \mathrm{MFI}$, and MOR. The Beta zeolite favors isomerized products desorption and diffusion due to weaker acidic sites. Nevertheless, the lower isomerization occurrence can be explained by the lower HT selectivity, because both cyclization and isoparaffins formation depend on HT for the formation of intermediary olefins.

Table 5 summarizes thiophene conversion results. Products formed from hydrogenation reactions $\left(\mathrm{H}_{2} \mathrm{~S}\right.$ and Tetrahydrothiophene compounds), cracking reactions (mercaptans), 
alkylation reactions (methyl, ethyl, and propyl thiophene), and condensation (benzo and dibenzothiophenes, and other heavy compounds).

The main product observed from the thiophene reaction for every catalyst was $\mathrm{H}_{2} \mathrm{~S}$ (Table 5). $\mathrm{Mg} \beta \mathrm{I}$ and $\mathrm{Mg} \beta \mathrm{E}$ catalysts presented lower selectivity to $\mathrm{H}_{2} \mathrm{~S}$ values. There are several reaction mechanisms in the literature that propose different reactional paths for the observed compounds formation in Table 5 (Jaimes et al., 2011; Potapenko et al., 2012). One can observe that catalytic cracking occurs by successive hydrogenations in the thiophene ring with the formation of hydro derivatives, and, finally, the production of $\mathrm{H}_{2} \mathrm{~S}$ (Valla et al., 2006). This mechanism depends, therefore, on the availability of hydrogen for these successive reactions, and is hence unfavored by the diminishment of $\mathrm{HT}$ among hydrocarbons. $\mathrm{H}_{2} \mathrm{~S}$ selectivity accompanies the $\mathrm{HT}$ reactions selectivity diminishment trend, as shown by the $I_{H T}{ }^{*}$ index (Equation 10). This is also coherent with what is expected since, in the array of reactions involving organosulfurized compounds, hydrogen transfer, which is a secondary catalytic paraffin cracking reaction, can promote thiophene reduction to $\mathrm{H}_{2} \mathrm{~S}$ through proton donation from hydrocarbons (Potapenko et al., 2012; Wen et al., 2012).
The addition of magnesium to the catalysts, for having unfavored HT selectivity among hydrocarbons, decreased the successive hydrogenation steps occurrence of intermediary products from thiophene and favored the preservation of alkylated compounds, and also the formation of cracked products from intermediates, particularly mercaptans, according to Figure 5.

Jaimes et al. (2009) while studying thiophene reaction on zeolites, considering the several products obtained, proposed that the alkylation reaction of thiophene can occur between a thiophene molecule and different hydrocarbon molecules adsorbed on neighboring active sites. According to Shan et al. (2002), these reactions occur by an electrophilic attack on $\alpha$ and $\beta$ thiophene molecule positions.

The increase in the number of moderate and strong active sites with the incorporation of magnesium into the Beta zeolite (Table 3 ) favors an increase in adsorptive capacity for these catalysts. Shan et al. (2002), while studying thiophenic compounds cracking mechanisms on USY zeolite, verified that the addition of zinc oxides to the zeolite increase the number of Lewis acidic sites in the zeolite. Thiophenic compounds were absorbed by these sites while the zeolite acts through Brønsted sites during cracking.

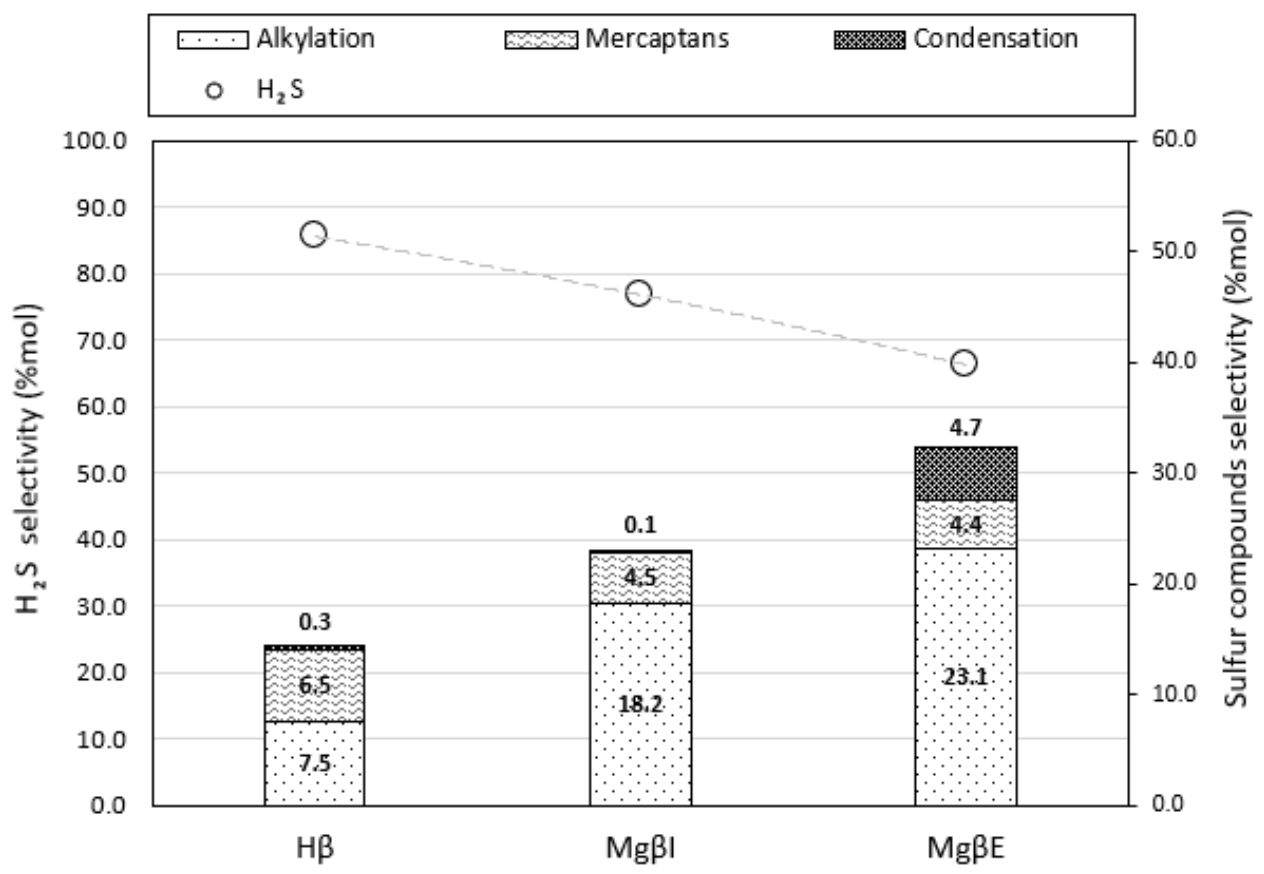

Figure 5. Organosulfur compounds groups selectivity diagram (\%mol). 
These Lewis sites, according to Wang et al. (1998), can be formed depending on the metal incorporation to the zeolite method. In cationic exchange, the presence of the cation $\mathrm{Mg}^{2+}$ and, in impregnation, the formation of $\mathrm{MgO}$, increase Lewis acidity in the zeolite. The formation of these species depends on preparation conditions and incorporated metal quantity.

One can infer that on the $M g \beta I$ and $M g \beta E$ catalyst surface, there was the formation of these different magnesium species, increasing the number of strong acidic sites in these catalysts. These sites, which neighbor Brønsted sites, favor a higher thiophene adsorption which reacts with the products formed in hexane cracking, and thiophene itself, increasing alkylated product formation and decreasing selectivity to cracked products, particularly mercaptans.

According to Dupain et al. (2013), both hydrocarbons and sulfurized compounds crack forming carbocations, and thiophenic compounds are adsorbed onto Lewis sites on the catalyst surface. Mao et al. (2015) while studying thiophene and its derivatives cracking mechanisms on pure and cationic exchanged by alkali metals Beta zeolite observed that metal addition to the Beta zeolite promotes an increase in adsorptive thiophene capacity.

\section{CONCLUSIONS}

The acidic characteristics and cracking reactions performance after magnesium incorporation into the Beta zeolite showed that this zeolite and the prepared catalysts are quite promising for catalytic cracking of sulfurized compounds.

The magnesium modification resulted in an increase in the number of Brønsted acidic sites, especially for the $\mathrm{Mg} \beta \mathrm{E}$ catalyst, when compared to the pure $\mathrm{H} \beta$ zeolite. The TPD- $\mathrm{NH}_{3}$ analysis demonstrated that magnesium addition promotes an increase in total acidity and the surge of stronger active sites over the decrease of the number of moderate and weak active sites.

The catalytic test with $\mathrm{n}$-hexane showed that the addition of magnesium promotes a cracking reaction selectivity increase and a decrease in isomerization reactions.
However, in the thiophene conversion case, the addition of magnesium to the Beta zeolite moderated HT selectivity compromised $\mathrm{H}_{2} \mathrm{~S}$ selectivity from organosulfur compounds, both for the modified Beta zeolite by impregnation and cationic exchange. The addition of magnesium led to the formation of larger quantities of alkylated products over the formation of $\mathrm{H}_{2} \mathrm{~S}$, and mercaptans, possibly due to the decreased HT selectivity and the increase in the number of Lewis sites, which promoted an increase in adsorptive capacity of olefinic compounds, facilitating this reaction.

\section{ACKNOWLEDGEMENTS}

This research was supported financially by the Brazilian Institute of Technology and Regulation IBTR. Thanks to the Laboratory of Catalyst Synthesis (LSCat) at UFAL and the IDEA Laboratory in the Chemistry Institute - UFBA - for the analysis.

\section{REFERENCES}

Abro, R.; Abdeltawab, A. A.; Al-Deyab, S. S.; Yu, G.; Qazi, A. B.; Gao, S.; Chen, X. A review of extractive desulfurization of fuel oils using ionic liquids. Rsc Advances, v. 4, n. 67, p. 35302-35317, 2014. https://doi.org/10.1039/C4RA03478C

Ahmad, W. Sulfur in petroleum: Petroleum desulfurization techniques. In: Applying Nanotechnology to the Desulfurization Process in Petroleum Engineering. Hershey, Pennsylvania: IGI Global, 2016. 540 p. https://doi.org/10.4018/978-14666-9545-0.ch001

Bajia, S. C.; Singh, R. J.; Bajia, B.; Kumar, S. Determination of sulfur content in petroleum products-an overview. Journal of Sulfur Chemistry, v. 38, n. 4, p. 450-464, 2017.

https://doi.org/10.1080/17415993.2017.1289530

Bhutto, A. W.; Abro, R.; Gao, S.; Abbas, T.; Chen, X.; Yu, G. Oxidative desulfurization of fuel oils using ionic liquids: A review. Journal of the Taiwan Institute of Chemical Engineers, v. 62, p. 84-97, 2016. https://doi.org/10.1016/i.jtice.2016.01.014 
Brunet, S.; Mey, D.; Pérot, G.; Bouchy, C.; Diehl, F. On the hydrodesulfurization of FCC gasoline: $A$ review. Applied Catalysis A: General, v. 278, n. 2, p. 143-172, 2005.

https://doi.org/10.1016/i.apcata.2004.10.012

Bryden, K.; Singh, U.; Berg, M.; Brandt, S.; Schiller, R.; Cheng, W. C. Fluid catalytic cracking (FCC): catalysts and additives. In: Kirk-Othmer Encyclopedia of Chemical Technology. New York: Wiley, 2015. 37 p.

https://doi.org/10.1002/0471238961.fluidnee.a01.pub2

Castro Dantas, T. N.; Dantas Neto, A. A., Moura, M. C. P. A., Barros Neto, E. L., Duarte, K. R. F. Study of new alternatives for removal of sulfur from diesel. Brazilian Journal of Petroleum and Gas, v. 8, n. 1, 2014. https://doi.org/10.5419/bjpg2014-0002

Clough, M.; Pope, J. C.; Lin, L. T. X.; Komvokis, V.; Pan, S. S.; Yilmaz, B. Nanoporous materials forge a path forward to enable sustainable growth: Technology advancements in fluid catalytic cracking. Microporous and Mesoporous Materials, v. 254, p. 45-58, 2017.

https://doi.org/10.1016/j.micromeso.2017.03.063

Corma, A.; Gonzalez-Alfaro, V.; Orchilles, A. V. Catalytic cracking of alkanes on MCM-22 zeolite. Comparison with ZSM-5 and beta zeolite and its possibility as an FCC cracking additive. Applied Catalysis A: General, v. 129, n. 2, p. 203-215, 1995. https://doi.org/10.1016/0926-860X(95)00081-X

Corma, A.; Sauvanaud, L. FCC testing at bench scale: New units, new processes, new feeds. Catalysis today, v. 218, p. 107-114, 2013. https://doi.org/10.1016/j.cattod.2013.03.038

Dehghan, R.; Anbia, M. Zeolites for adsorptive desulfurization from fuels: A review. Fuel Processing Technology, v. 167, p. 99-116, 2017. https://doi.org/10.1016/i.fuproc.2017.06.015

Dupain, X.; Rogier, L. J.; Gamas, E. D.; Makkee, M.; Moulijn, J. A. Cracking behavior of organic sulfur compounds under realistic FCC conditions in a microriser reactor. Applied Catalysis A: General, v. 238, n. 2, p. 223-238, 2003.

https://doi.org/10.1016/S0926-860X(02)00367-8

Farneth, W. E.; Gorte, R. J. Methods for characterizing zeolite acidity. Chemical reviews, v. 95, n. 3, p. 615-635, 1995.

https://doi.org/10.1021/cr00035a007
Gong, Y.; Dou, T.; Kang, S.; Li, Q.; Hu, Y. Deep desulfurization of gasoline using ion-exchange zeolites: $\mathrm{Cu}$ (I)-and $\mathrm{Ag}$ (I)-beta. Fuel processing technology, v. 90, n. 1, p. 122-129, 2009. https://doi.org/10.1016/i.fuproc.2008.08.003

Hernando, H.; Moreno, I.; Fermoso, J.; OchoaHernández, C.; Pizarro, P.; Coronado, J. M.; Čejka, J.; Serrano, D. P. Biomass catalytic fast pyrolysis over hierarchical ZSM-5 and Beta zeolites modified with $\mathrm{Mg}$ and $\mathrm{Zn}$ oxides. Biomass Conversion and Biorefinery, v. 7, n. 3, p. 289-304, 2017. https://doi.org/10.1007/s13399-017-0266-6

Hopkins, P. D.; Marshall, C.; Miller, J.; Raska, L. Hexane Cracking on Clean Zeolite Surfaces. In: Studies in Surface Science and Catalysis. Elsevier, 1988. p. 281- 293.

Ibrahim, M. H.; Hayyan, M.; Hashim, M. A.; Hayyan, $A$. The role of ionic liquids in desulfurization of fuels: A review. Renewable and Sustainable Energy Reviews, v. 76, p. 1534-1549, 2017. https://doi.org/10.1016/i.rser.2016.11.194

Iruretagoyena, D.; Montesano, R. Selective Sulfur Removal from Liquid Fuels Using Nanostructured Adsorbents. In: Nanotechnology in Oil and Gas Industries. Springer, Cham, 2018. p. 133-150. https://doi.org/10.1007/978-3-319-60630$\underline{95}$

Jaimes, L.; Badillo, M.; De Lasa, H. FCC gasoline desulfurization using a ZSM-5 catalyst: Interactive effects of sulfur containing species and gasoline components. Fuel, v. 90, n. 5, p. 2016-2025, 2011. https://doi.org/10.1016/j.fuel.2010.12.041

Jaimes, L.; Ferreira, M. L.; de Lasa, H. Thiophene conversion under mild conditions over a ZSM-5 catalyst. Chemical Engineering Science, v. 64, n. 11, p. 2539-2561, 2009. https://doi.org/10.1016/i.ces.2009.01.070

Karthikeyani, A. V.; Anantharaman, N.; Prabhu, K. M.; Kumaresan, L.; Pulikottil, C. A.; Ramakumar, S. S. V. In situ FCC gasoline sulfur reduction using spinel based additives. International Journal of Hydrogen Energy, v. 42, n. 42, p. 26529- 26544, 2017. https://doi.org/10.1016/j.ijhydene.2017.08.006 
Knott, B. C.; Nimlos, C. T.; Robichaud, D. J.; Nimlos, M. R.; Kim, S.; Gounder, R. Consideration of the Aluminum Distribution in Zeolites in Theoretical and Experimental Catalysis Research. ACS Catalysis, v.8, n.2, 770-784, 2018. https://doi.org/10.1021/acscatal.7b03676

Lersch, P.; Bandermann, F. Conversion of chloromethane over metal-exchanged ZSM-5 to higher hydrocarbons. Applied catalysis, v. 75, n. 1, p. 133-152, 1991. https://doi.org/10.1016/S0166$\underline{9834(00) 83129-2}$

Lónyi, F.; Valyon, J. A TPD and IR study of the surface species formed from ammonia on zeolite $\mathrm{H}$ ZSM-5, H-mordenite and H-beta., Thermochimica acta, v. 373, n. 1, p. 53-57, 2001.

https://doi.org/10.1016/S0040-6031(01)00458-0

Lukyanov, D. B. A test method for quantitative characterization of zeolite hydrogen transfer activity. Journal of Catalysis, v. 145, n. 1, p. 54-57, 1994. https://doi.org/10.1006/icat.1994.1006

Mao, X.; Sun, Y.; Pei, S. A theoretical investigation into thiophenic derivative cracking mechanism over acidic and cation-exchanged beta zeolites. Computational and Theoretical Chemistry, v. 1074, p. 112-124, 2015. https://doi.org/10.1016/i.comptc.2015.10.019

Mirodatos, C.; Abou Kais, A.; Vedrine, J. C.; Pichat, P.; Barthomeuf, D. Correlations of cracking properties of $\mathrm{Mg}-\mathrm{Y}$ zeolites with their acidic and basic sites. The Journal of Physical Chemistry, v. 80, n. 21, p. 2366-2371, 1976.

https://doi.org/10.1021/j100562a010

Morais, V. S.; Filgueiras, P. R.; Castro, E. V. R.; Mota, M. F. B.; Malacarne, M. M.; Morigaki, M. K. Investigating petroleum profiles and composition of petroleum fractions by means of sulfur analyses. Brazilian Journal of Petroleum and Gas, v. 4, n. 1, 2010.

Nuhu, A. A. Bio-catalytic desulfurization of fossil fuels: a mini review. Reviews in Environmental Science and Bio/Technology, v. 12, n. 1, p. 9-23, 2013. https://doi.org/10.1007/s11157-012-9267-x

Olson, D. H.; Haag, W. O.; Lago, R. M. Chemical and physical properties of the ZSM-5 substitutional series. Journal of Catalysis, v. 61, n. 2, p. 390-396, 1980. https://doi.org/10.1016/0021-9517(80)90386-3
Peng, L.; Ni, Y.; Wei, X.; Hanyu, W.; Duoqiang, P.; Wangsuo, W. Removal of $U(\mathrm{VI})$ from aqueous solution using $\mathrm{TiO}_{2}$ modified $\beta$-zeolite., Radiochimica Acta, v. 105, n. 12, p. 1005-1013, 2017. https://doi.org/10.1515/ract-2017-2765

Potapenko, O. V.; Doronin, V. P.; Sorokina, T. P. Influence of $[H]$-donating activity of hydrocarbons on transformations of thiophene compounds under catalytic cracking conditions. Petroleum Chemistry, v. 52, n. 1, p. 55-59, 2012.

https://doi.org/10.1134/S0965544112010082

Potapenko, O. V.; Doronin, V. P.; Sorokina, T. P.; Krol, O. V.; Likholobov, V. A. A study of intermolecular hydrogen transfer from naphthenes to 1-hexene over zeolite catalysts. Applied Catalysis A: General, v. 516, p. 153-159, 2016. https://doi.org/10.1016/i.apcata.2016.02.028

Pusparatu, H. Y.; Aoyama, K.; Komura, K.; Kubota, Y.; Nishimura, Y.; Sugi, Y. Isomerization and cracking of hexane over beta zeolites synthesized by dry gel conversion method. Journal of the Japan Petroleum Institute, v. 55, n. 2, p. 120-131, 2012. https://doi.org/10.1627/ipi.55.120

Santos, J. H. L.; Lima Filho, N. M.; Duarte, M. M. M. B.; Chiaro, S. S. X.; Barbosa, C. M. B. M. NaY zeolites impregnated with nickel for adsorption of sulfur compounds from fuel model mixture. Brazilian Journal of Petroleum and Gas, v. 7, n. 3, 2013. https://doi.org/10.5419/bjpg2013-0010

Shan, H. H.; Li, C. Y.; Yang, C. H.; Zhao, H.; Zhao, B. Y.; Zhang, J. F. Mechanistic studies on thiophene species cracking over USY zeolite. Catalysis Today, v. 77, n. 1-2, p. 117-126, 2002.

https://doi.org/10.1016/S0920-5861(02)00238-9

Siddiqui, M. B.; Ahmed, S.; Aitani, A. M.; Dean, C. F. Sulfur reduction in FCC gasoline using catalyst additives. Applied Catalysis A: General, v. 303, n. 1, p. 116- 120, 2006.

https://doi.org/10.1016/i.apcata.2006.02.012

Tian, F.; Yang, X.; Shi, Y.; Jia, C.; Chen, Y. Adsorptive desulfurization over hierarchical beta zeolite by alkaline treatment. Journal of Natural Gas Chemistry, v. 21, n. 6, p. 647-652, 2012. https://doi.org/10.1016/S1003-9953(11)60414-3 
Valla, J. A.; Lappas, A. A.; Vasalos, I. A. A. Catalytic cracking of thiophene and benzothiophene: Mechanism and kinetics. Applied Catalysis A: General, v. 297, n. 1, p. 90-101, 2006. https://doi.org/10.1016/i.apcata.2005.08.049

Vargas-Tah, A. A.; García, R. C.; Archila, L. F. P.; Solis, J. R.; López, A. J. G. A study on sulfur reduction in FCC gasoline using $\mathrm{Zn}-\mathrm{Mg}-\mathrm{Al}$ spinels. Catalysis Today, v. 107, p. 713-718, 2005.

https://doi.org/10.1016/i.cattod.2005.07.001

Wang, Y.; Zhu, J. H.; Cao, J. M.; Chun, Y.; Xu, Q. $\mathrm{H}$. Basic catalytic behavior of $\mathrm{MgO}$ directly dispersed on zeolites by microwave irradiation. Microporous and mesoporous materials, v. 26, $n$. 1-3, p. 175-184, 1998.

https://doi.org/10.1016/S1387-1811(98)00231-5

Ward, J. W. The nature of active sites on zeolites: III. The alkali and alkaline earth ionexchanged forms. Journal of Catalysis, v. 10, n. 1, p. 34-46, 1968 . https://doi.org/10.1016/00219517(68)90220-0
Wen, Y.; Wang, G.; Xu, C.; Gao, J. Study on in situ sulfur removal from gasoline in fluid catalytic cracking process. Energy \& Fuels, v. 26, n. 6, p. 3201-3211, 2012.

https://doi.org/10.1021/ef300499j

Zhang, Q.; Ming, W.; Ma, J.; Zhang, J.; Wang, P.; $\mathrm{Li}, \mathrm{R}$. De novo assembly of a mesoporous beta zeolite with intracrystalline channels and its catalytic performance for biodiesel production. Journal of Materials Chemistry A, v. 2, n. 23, p. 8712-8718, 2014.

https://doi.org/10.1039/C4TA00030G

Zhang, Y.; Maesen, T. L. M. Middle distillate hydrocracking catalyst. U.S. Patent n. 9,944,863, 17 abr. 2018. 